\title{
Suicidal Expression in Adolescents in Nicaragua in Relation to Youth Self- Report (YSR) Syndromes and Exposure to Suicide
}

\author{
Claudia María Obando Medina ${ }^{1, *}$, Andres Herrera ${ }^{2}$ and Gunnar Kullgren ${ }^{3}$ \\ ${ }^{1}$ Centre for Demography and Health Research. Nicaraguan National Autonomous University, León, Nicaragua \\ ${ }^{2}$ Centre for Demography and Health Research. Nicaraguan National Autonomous University, León, Nicaragua \\ ${ }^{3}$ Department of Clinical Sciences, Division of Psychiatry, Umeå University, Sweden
}

\begin{abstract}
:
Background: Suicide and suicidal expressions among young people represent a major public health problem worldwide. Most studies are from high-income countries, and it remains unclear whether prevalence and risk factors show a similar pattern in other settings. This study aims to assess the prevalence of suicidal expressions and serious suicidal expressions (ideation, plans and attempts) among adolescents in Nicaragua, in relation to previously reported risk factors, such as exposure to suicide in significant others (parents, siblings, partners or friends) and mental health problems.

Methods: 368 adolescents aged 15-18 years were randomly selected from public secondary schools in León, Nicaragua. Data was collected using Attitude Towards Suicide (ATTS) and Youth Self-Report questionnaires (YSR). Bivariate and multivariate analyses were conducted.

Results: Suicide ideation prevalence in the past year was $22.6 \%$, suicide plans $10.3 \%$, and suicide attempts $6.5 \%$. Girls were significantly more likely to report suicidal ideation. Multivariate analyses showed that anxious/depressed, somatic complaints and exposure to suicidal behavior in significant others were significantly associated with own serious suicidal expressions.

Conclusions: The prevalence of serious suicidal expressions among young people in Nicaragua is within the range reported from Western high-income countries. An attempted or completed suicide in someone close, is associated with own suicidal expressions even in the absence of increased mental distress. Furthermore, somatic complaints should alert health care professionals of the possibility of increased suicide risk.
\end{abstract}

Key Words: Suicidal expressions, youth self report, nicaragua, school based.

\section{INTRODUCTION}

Worldwide, suicide is one of the three leading causes of death among people aged 15-34 years [1-3], and suicide rates are increasing in this age group in most parts of the world [4]. Suicidal expressions are strongly associated with suicide, and suicide attempts represent the single strongest predictor of a future suicide [5-8]. It has been estimated that for every suicide there are at least ten suicide attempts [2,3]. In a school-based study from New Zealand, $15.2 \%$ of adolescents reported a life-time suicide attempt [9]. Other suicidal expressions, such as ideation and plans, are also significant risk factors for completed suicides and important indicators of mental health problems $[10,11]$. A population-based study from the U.S. [12] found that suicide ideation was most common among young people aged 18-24 years. There are not so many studies from low-income countries on risk factors for suicidal expressions among young people. Two studies from India have shown a number of factors to be

*Address correspondence to this author at the Centre for Demography and Health Research, Nicaraguan National Autonomous University, León, Nicaragua; Tel: (505) 2311 - 0368; Fax: (505) 2311 - 0368;

E-mail: claudia.obando@psychiat.umu.se, associated with suicidal expressions such as psychological distress, physical and sexual abuse and alcohol use [13, 14]. A school based survey in four countries representing four continents found factors associated with suicidal behavior to be quite similar in all four settings [15]. In terms of prevalence, a Nicaraguan community based study showed that prevalence of suicidal expressions (defined as ideation, plans, thoughts, and attempts in the last 12 months) was $20 \%$ among young people aged 15 to 24 years [16], quite similar to findings from an Iranian study [17].

Gender patterns in suicidal behavior are complex [18, 19]. For completed suicides, rates are equal for young men and women in some Asian countries, in China even higher among females, whereas in most other countries completed suicide among young people 15-24 years of age are more common among men [20,21]. Obviously, ethnicity and culture plays an important role [22]. In Nicaragua, the overall suicide rate is the highest among the Central and South American countries, and young men have higher rates than young women [23].

Regarding hospital based suicide attempts there is a strong preponderance for girls worldwide [3, 24, 25]. In Nicaragua in a hospital-based study, suicide attempt rates 
among young people aged 15-19 years were more than three times higher among girls than boys [25]. However, selfreported suicidal expressions showed few gender differences in a community-based study in the same area [16].

A number of factors have been suggested to be associated with suicidal expressions. A systematic review of population-based studies has listed a number of such factors, including mental and physical health problems, family characteristics, and social factors [26]. Gender identity problems has been also reported as a risk factor for suicide attempts $[27,28]$.

Several studies have also shown an association between being exposed to suicidal behaviors in significant others and own suicidal expressions. For example, a Chinese study reported that high-intent suicidal acts were associated with having a relative with a suicidal history [29]. Furthermore, suicide attempts seem to be contagious between adolescents. In two studies from the United States, the greatest risk factor for suicide attempts among male and female youths was having a friend who had attempted or completed suicide [28, 30]. Similar findings have been reported from Nicaragua [16].

Most studies on risk factors have been conducted in the Western world, especially North America, and it is clear that that more research is needed before extrapolating findings to other countries and cultures $[19,28]$. The aims of the current study are firstly to assess the prevalence of suicidal expressions among adolescents aged 15-18 years in a school population in Nicaragua, and secondly to examine the association between serious suicidal expressions and mental syndromes according to YSR, exposure to suicide and alcohol use.

\section{METHOD}

\section{Study Setting}

Nicaragua's population is predominantly young $37 \%$ are under 15 years and 59\% of productive age (15-64 years). Leon is Nicaragua's second-largest city with a population of around 174,000 [31]. Young people in Nicaragua face many challenges: the unemployment rate is high, emigration disrupts family structure [32], and dropping out of school is common [33]. Alcohol and drug problems are increasing [34]. Primary education is free and compulsory for children aged 6 up to 15 years of age. Secondary education is also free but not compulsory [35]. Fifty-nine percent of students attend public schools in León municipality; the illiteracy rate is $7.1 \%$. [35]

\section{Study Design and Sample}

We conducted a cross-sectional study among students aged 15-18 years in all nine public urban secondary schools in Leon municipality, Nicaragua, during the first six months of 2008. According to the school records, 3162 pupils in the chosen age group attended day school in the first to fifth grade during the study period. The size of the study was judged to be sufficiently large to accurately measure the magnitude of suicidal expression in students from secondary schools. Using an expected prevalence of any suicidal expression of 59\% as reported in a previous Nicaraguan study [16], with a precision and confidence level of 5\% and 95\%, respectively, a sample size of 370 students adjusted by a rejection rate of $10 \%$ was found appropriate. The calculation was conducted using Epi Info 6.0.

A random stratified sampling technique was applied proportional to the size of each school. Within each school, students were selected by simple random sampling. The sampling procedure is illustrated further in Fig. (1).

Of the 368 respondents $51 \%$ were boys, with a mean age of $16.1 \pm 1.03 \mathrm{SD}$ years compared to $16.3 \pm 1.02 \mathrm{SD}$ years for the girls. $15.3 \%$ of the students were in the first or second high school grade, $34 \%$ in the third grade, $27.4 \%$ in the fourth, and $23.4 \%$ in the fifth.

\section{Data Collection}

Based on the list of students selected to participate, 370 were invited to participate on a special day agreed with the principal of each school. Two students from two different schools did not participate due to transportation problems. Those who were selected were invited to a special room, where the main researcher explained the objectives of the study and emphasized that participation was fully voluntary and anonymous. Verbal consent was obtained, with all invited students choosing to participate. Careful instructions were then given on how to complete the questionnaires. Two trained field workers were available to clarify any questions.

\section{Instrument and Measures}

Data were obtained on socio-demographic characteristics such as age, sex, and educational level. Two instruments were used for data collection. Section one of the Attitudes Towards Suicide (ATTS) scale was used to measure lifetime exposure to attempted and completed suicides among significant others (parents, siblings, partners and friends). The third section of the same instrument was used to determine own suicidal expressions during the last twelve months, suicidal expressions such as life-weariness, deaths wishes, suicidal ideation, suicidal plans, suicide attempt. Serious suicidal expressions was defined as ideation, plans and attempts in the last 12 months, statements in the instruments that explored suicidal expressions are like: "During the past year have you often felt that life is not meaningful", "During the past year have you reached the point where you seriously considered taking your life, or perhaps made plans how you would go about doing it?" It has been used previously in Nicaragua $[16,36]$.

Emotional and behavioral problems were assessed using the Youth Self-Report (YSR) [37]. The YSR is a component of the Achenbach System of Empirically Based Assessment (ASEBA). It is a self-report questionnaire for 11-18 year olds, divided in two parts: Competencies, and Behavioral and Emotional Symptoms. In the current study only the latter part was included. This consists of 112 items: the responses are 0 , not true; 1 , somewhat or sometimes true; and 2, very true or often true. It assesses a comprehensive set of behavioral and emotional symptoms which in the analysis are combined into eight syndromes. The syndromes are further combined into internalizing and externalizing scales [37]. All scores refer to symptoms during recent six months. 


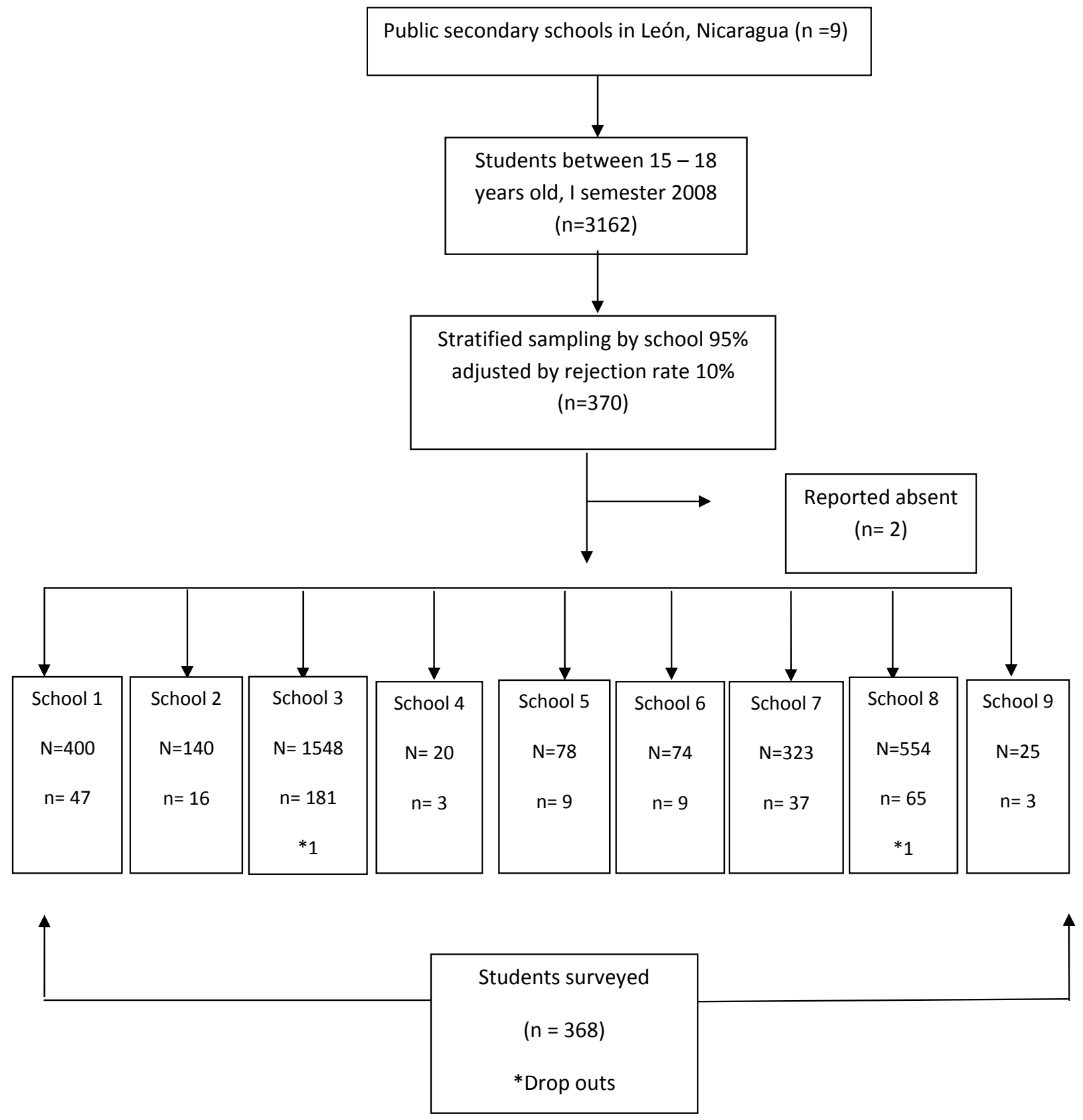

Fig. (1). Study sampling strategy. Suicidal expressions among adolescents in a school sample in León, Nicaragua.

\section{Internal Consistency}

Internal consistency for Youth Self Report syndrome scales internal consistency scores was determined with Cronbach's alpha. It varied from 0.63 for the withdrawn scale to 0.77 for the aggressive behaviour scale. Internalizing and externalizing syndromes scored 0.77 and 0.78 respectively.

Alcohol consumption in the last six months was measured using item 2 in the Youth Self-Report (YSR) [37], "I drink alcohol without my parents' approval."

The YSR has been extensively validated in several cultures and countries [37]. To assess the applicability of the instrument in a Nicaraguan context, the Spanish YSR version was tested in a pilot study with 100 young students from outside the study area. As a result, some minor linguistic changes were made to adapt it to Nicaraguan culture.

\section{Analysis}

The statistical package SPSS version 16 (SPSS, Chicago, IL) was used for bi- and multivariate analyses. Chi-square and t-tests were used to analyze distributions and compare means, respectively. For the multivariate analyses, YSR syndromes were dichotomized by means of a $90^{\text {th }}$ percentile gender-specific split. The Receiver Operating Characteristic (ROC) and Area Under the Curve (AUC) were used to evaluate the overall performance of YSR internalizing and externalizing scales as predictors for serious suicidal expressions. 
Table 1. Suicidal Expressions Stratified by Gender Among Adolescents in a School Sample in León, Nicaragua

\begin{tabular}{|c|c|c|c|c|c|c|c|}
\hline \multicolumn{2}{|c|}{ Suicidal Expressions } & \multicolumn{2}{|c|}{$\begin{array}{c}\text { Boys } \\
n=188\end{array}$} & \multicolumn{2}{|c|}{$\begin{array}{c}\text { Girls } \\
\mathrm{n}=\mathbf{1 8 0}\end{array}$} & \multicolumn{2}{|c|}{$\begin{array}{c}\text { Total } \\
\mathbf{n}=\mathbf{3 6 8}\end{array}$} \\
\hline & & $\mathbf{n}$ & $\%$ & $\mathbf{n}$ & $\%$ & $\mathbf{n}$ & $\%$ \\
\hline Life not meaningful & $\begin{array}{l}\text { No } \\
\text { Yes }\end{array}$ & $\begin{array}{c}50 \\
138\end{array}$ & $\begin{array}{l}26.6 \\
73.4\end{array}$ & $\begin{array}{c}32 \\
148\end{array}$ & $\begin{array}{l}17.8 \\
82.2\end{array}$ & $\begin{array}{c}82 \\
286\end{array}$ & $\begin{array}{l}22.3 \\
77.7\end{array}$ \\
\hline Life weariness & $\begin{array}{l}\text { No } \\
\text { Yes }\end{array}$ & $\begin{array}{c}124 \\
64\end{array}$ & $\begin{array}{l}66.0 \\
34.0\end{array}$ & $\begin{array}{c}118 \\
62\end{array}$ & $\begin{array}{l}65.6 \\
34.4\end{array}$ & $\begin{array}{l}242 \\
126\end{array}$ & $\begin{array}{l}65.8 \\
34.2\end{array}$ \\
\hline Death thought & $\begin{array}{l}\text { No } \\
\text { Yes }\end{array}$ & $\begin{array}{c}120 \\
68\end{array}$ & $\begin{array}{l}63.8 \\
36.2\end{array}$ & $\begin{array}{c}102 \\
78\end{array}$ & $\begin{array}{l}56.7 \\
43.3\end{array}$ & $\begin{array}{l}222 \\
146\end{array}$ & $\begin{array}{l}60.3 \\
39.7\end{array}$ \\
\hline Death wishes & $\begin{array}{l}\text { No } \\
\text { Yes }\end{array}$ & $\begin{array}{c}141 \\
47\end{array}$ & $\begin{array}{l}75.0 \\
25.0\end{array}$ & $\begin{array}{c}119 \\
61\end{array}$ & $\begin{array}{l}66.1 \\
33.9\end{array}$ & $\begin{array}{l}260 \\
108\end{array}$ & $\begin{array}{l}70.7 \\
29.3\end{array}$ \\
\hline Suicide attempts & $\begin{array}{l}\text { No } \\
\text { Yes }\end{array}$ & $\begin{array}{c}178 \\
10\end{array}$ & $\begin{array}{c}94.7 \\
5.3\end{array}$ & $\begin{array}{c}166 \\
14\end{array}$ & $\begin{array}{c}92.2 \\
7.8\end{array}$ & $\begin{array}{c}344 \\
24\end{array}$ & $\begin{array}{c}93.5 \\
6.5\end{array}$ \\
\hline
\end{tabular}

Multivariate analyses were conducted with serious suicidal expressions as dependent variable and dichotomized YSR syndromes, alcohol consumption and exposure to significant others' as co-variates.

\section{Ethics}

The protocol was submitted and approved by the Ethics Committee of UNAN León University, Nicaragua and Umeå University (07-046M), Sweden. In addition, we obtained the approval of the Nicaraguan Education Ministry representative in León municipality. We visited each school and explained the objectives of the study to the principal and teachers. The procedure of inviting selected students strived to ensure voluntary participation. Free referral services were made available to students who might need them.

\section{RESULTS}

One-year prevalence of different suicidal expressions among boys and girls are shown in Table 1. Girls were significantly more likely than boys to report at least one suicidal expression in the past year $(p=0.02)$. When we explored gender differences for each suicidal expression, girls scored significantly higher on items reflecting feelings that Life is not meaningful $(\mathrm{p}=.042)$ and Suicide ideation in the last year $(\mathrm{p}=.019)$. However, no significant gender differences were found when assessing one-year prevalence of the serious suicidal expressions.

Scores on YSR syndrome scales for boys and girls are shown in Table $\mathbf{2}$. For both genders, mean scores on all syndrome scales were significantly higher among those who reported a serious suicidal expression in the last year.

As shown in Fig. (2), ROC curves for externalizing and internalizing scales were analyzed in relation to serious suicidal expressions. Both scales were significantly associated with serious suicidal expressions. The area under the ROC curve (AUC) for the externalizing scale was .688 $(95 \%$ $\mathrm{CI}=.625-.751)$ and for the internalizing scale $.702(95 \% \mathrm{CI}=$ .636- .769) (Fig. 2).

Exposure to suicide in significant others was reported by overall $26.4 \%$ and many had several exposures (parents $5.7 \%$, or siblings $4.4 \%$, partner $8.2 \%, 25.8 \%$ friends). To further analyze the association between YSR syndrome scales and exposure to suicide, mean scores of YSR syndrome scales were compared between those exposed and those not exposed to suicidal behavior in significant others, respectively, as shown in Table 3. Altogether 97 respondents (26.4\%) reported exposure to suicide behavior in significant others. Mean scores on YSR syndrome scale values were significantly higher for those exposed to suicidal behavior in significant others for all scales except Withdrawn YSR syndrome (Table $\mathbf{3}$ ).

Crude odd ratios showed YSR syndromes, alcohol consumption and exposure to suicide among significant others to be significantly associated with serious suicidal expressions. After multivariate analysis where all variables were adjusted for, 318 respondents $(86.6 \%)$ were included due to missing data one some items. Anxious/depressed ( $\mathrm{OR}=3,30 ; 95 \%$ $\mathrm{CI}=1.33-8.21)$; somatic complaints syndromes $(\mathrm{OR}=2.86$; 95\% $\mathrm{CI}=1.29-6.35)$ and exposure to suicide among significant others $(\mathrm{OR}=2.52 ; 95 \% \mathrm{CI}=1.40-4.54)$ remained significant in the multivariate model (Table 4).

\section{DISCUSSION}

Suicidal expressions are common among Nicaraguan young people and $25 \%$ reported a serious suicidal expression during last year. Prevalence of suicidal expression varied by gender. Whereas girls more often reported milder suicidal expressions, there was no significant difference on prevalence of serious suicidal expressions by gender. Mental health problems were common and higher than reported 
Table 2. YSR Syndromes Scales Stratified by Sex and Serious Suicidal Expressions Among Adolescents in a School Sample in León, Nicaragua

\begin{tabular}{|c|c|c|c|c|c|c|c|c|c|c|c|c|}
\hline \multirow{3}{*}{$\begin{array}{c}\text { ITEMS } \\
\\
\begin{array}{c}\text { YSR Syndrome } \\
\text { Scales }\end{array}\end{array}$} & \multicolumn{6}{|c|}{ BOYS } & \multicolumn{6}{|c|}{ GIRLS } \\
\hline & \multicolumn{2}{|c|}{$\begin{array}{c}\text { Serious Suicidal } \\
\text { Expressions } \\
\mathbf{n}=\mathbf{4 0}\end{array}$} & \multicolumn{2}{|c|}{$\begin{array}{l}\text { No Serious Sui- } \\
\text { cidal Expression } \\
\quad n=148\end{array}$} & \multirow[b]{2}{*}{$\mathbf{t}$} & \multirow[b]{2}{*}{$\mathbf{p}$} & \multicolumn{2}{|c|}{$\begin{array}{c}\text { Serious Suicidal } \\
\text { Expressions } \\
\mathbf{n = 5 2}\end{array}$} & \multicolumn{2}{|c|}{$\begin{array}{c}\text { No Serious Suici- } \\
\text { dal Expression } \\
\mathbf{n = 1 2 8}\end{array}$} & \multirow[b]{2}{*}{$\mathbf{t}$} & \multirow[b]{2}{*}{$\mathbf{p}$} \\
\hline & Mean & SD & Mean & SD & & & Mean & SD & Mean & SD & & \\
\hline Anxious/Depressed & 5.8 & 2.8 & 3.9 & 2.3 & 4.4 & 0.00 & 7.0 & 2.9 & 4.5 & 2.6 & 5.6 & 0.00 \\
\hline Withdrawn & 4.8 & 1.8 & 3.7 & 1.8 & 3.4 & 0.00 & 4.5 & 2.2 & 3.9 & 2.0 & 1.7 & 0.07 \\
\hline Somatic Complaints & 3.8 & 2.7 & 2.9 & 2.2 & 2.1 & 0.03 & 5.0 & 2.6 & 3.6 & 2.0 & 3.4 & 0.00 \\
\hline Social problems & 5.6 & 2.4 & 4.1 & 2.3 & 3.6 & 0.00 & 5.2 & 2.6 & 4.0 & 2.4 & 2.9 & 0.00 \\
\hline Thought problems & 3.7 & 2.5 & 2.5 & 2.0 & 3.1 & 0.00 & 3.2 & 2.1 & 2.2 & 1.8 & 3.2 & 0.00 \\
\hline Attention problems & 5.1 & 2.0 & 4.3 & 2.4 & 1.9 & 0.05 & 5.1 & 2.3 & 3.7 & 2.2 & 3.8 & 0.00 \\
\hline Delinquent behaviour & 6.5 & 2.9 & 4.5 & 2.7 & 4.0 & 0.00 & 4.2 & 2.6 & 2.7 & 2.0 & 3.7 & 0.00 \\
\hline Aggressive behaviour & 8.6 & 2.9 & 6.3 & 3.6 & 3.7 & 0.00 & 7.8 & 3.2 & 5.8 & 3.1 & 3.8 & 0.00 \\
\hline Internalizing & 14.6 & 6.4 & 10.5 & 5.4 & 4.0 & 0.00 & 16.6 & 6.6 & 12.2 & 5.6 & 4.5 & 0.00 \\
\hline Externalizing & 15.2 & 5.3 & 10.9 & 5.9 & 4.1 & 0.00 & 12.1 & 5.2 & 8.4 & 4.7 & 4.6 & 0.00 \\
\hline
\end{tabular}

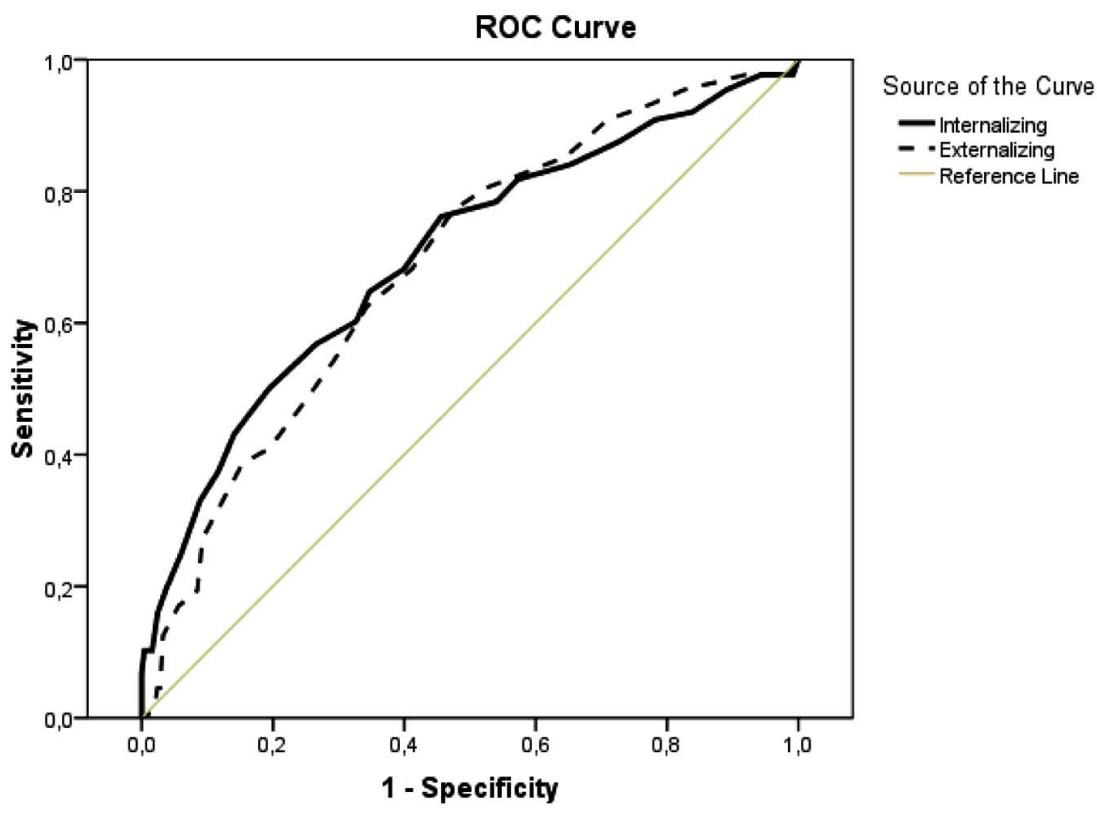

Diagonal segments are produced by ties.

Fig. (2). YSR internalizing and externalizing scores as predictors for serious suicidal expressions.

from normative US samples [37]. Exposure to suicide in significant others was also high where one fourth reported an attempt or completed suicide by someone close to them. Factors associated with own serious suicidal expression differed between genders. Among all, exposure to suicidal behaviour in significant others, anxious/depressed and somatic complaints YSR syndromes were strongly associated with own serious suicidal expression.
The prevalence of suicidal expression, such as suicide ideation, plans, and attempts, was within the range reported by other international studies [11,38-42]. Even if it failed to reach significance, girls were more likely to report plans and attempts than boys. This is consistent with previous studies from other countries $[21,39,41]$. One explanation suggested for this gender difference is that boys do not make as many attempts as girls; however, they use more severe methods 
Table 3. YSR Syndrome Scales Stratified by Exposure to Suicide Among Adolescents in a School Sample in León, Nicaragua

\begin{tabular}{|c|c|c|c|c|c|c|}
\hline \multirow{2}{*}{$\begin{array}{c}\text { ITEMS } \\
\text { YSR Syndrome Scales }\end{array}$} & \multicolumn{2}{|c|}{$\begin{array}{c}\text { Exposure } \\
n=97\end{array}$} & \multicolumn{2}{|c|}{$\begin{array}{c}\text { No Exposure } \\
\mathbf{n}=\mathbf{2 7 1}\end{array}$} & \multirow[b]{2}{*}{$\mathbf{t}$} & \multirow[b]{2}{*}{$\mathbf{p}$} \\
\hline & Mean & SD & Mean & SD & & \\
\hline Anxious/Depressed & 5.7 & 3.0 & 4.5 & 2.7 & 3.4 & 0.001 \\
\hline Withdrawn & 4.3 & 2.0 & 3.9 & 2.0 & 1.6 & 0.081 \\
\hline Somatic Complaints & 4.0 & 2.5 & 3.4 & 2.3 & 2.3 & 0.026 \\
\hline Social problems & 5.1 & 2.6 & 4.2 & 2.5 & 3.0 & 0.003 \\
\hline Thought problems & 3.3 & 2.2 & 2.4 & 2.0 & 3.5 & 0.001 \\
\hline Attention problems & 4.8 & 2.4 & 4.2 & 2.4 & 2.2 & 0.031 \\
\hline Delinquent behaviour & 4.6 & 2.8 & 3.9 & 2.8 & 2.2 & 0.029 \\
\hline Aggressive behaviour & 7.5 & 3.6 & 6.3 & 3.4 & 3.0 & 0.004 \\
\hline Internalizing & 14.2 & 6.5 & 11.8 & 5.9 & 3.0 & 0.003 \\
\hline Externalizing & 12.1 & 5.8 & 10.2 & 5.6 & 2.8 & 0.005 \\
\hline
\end{tabular}

Table 4. YSR Syndrome Scales as Related to Serious Suicidal Expressions Among Adolescents in a School Sample in León, Nicaragua

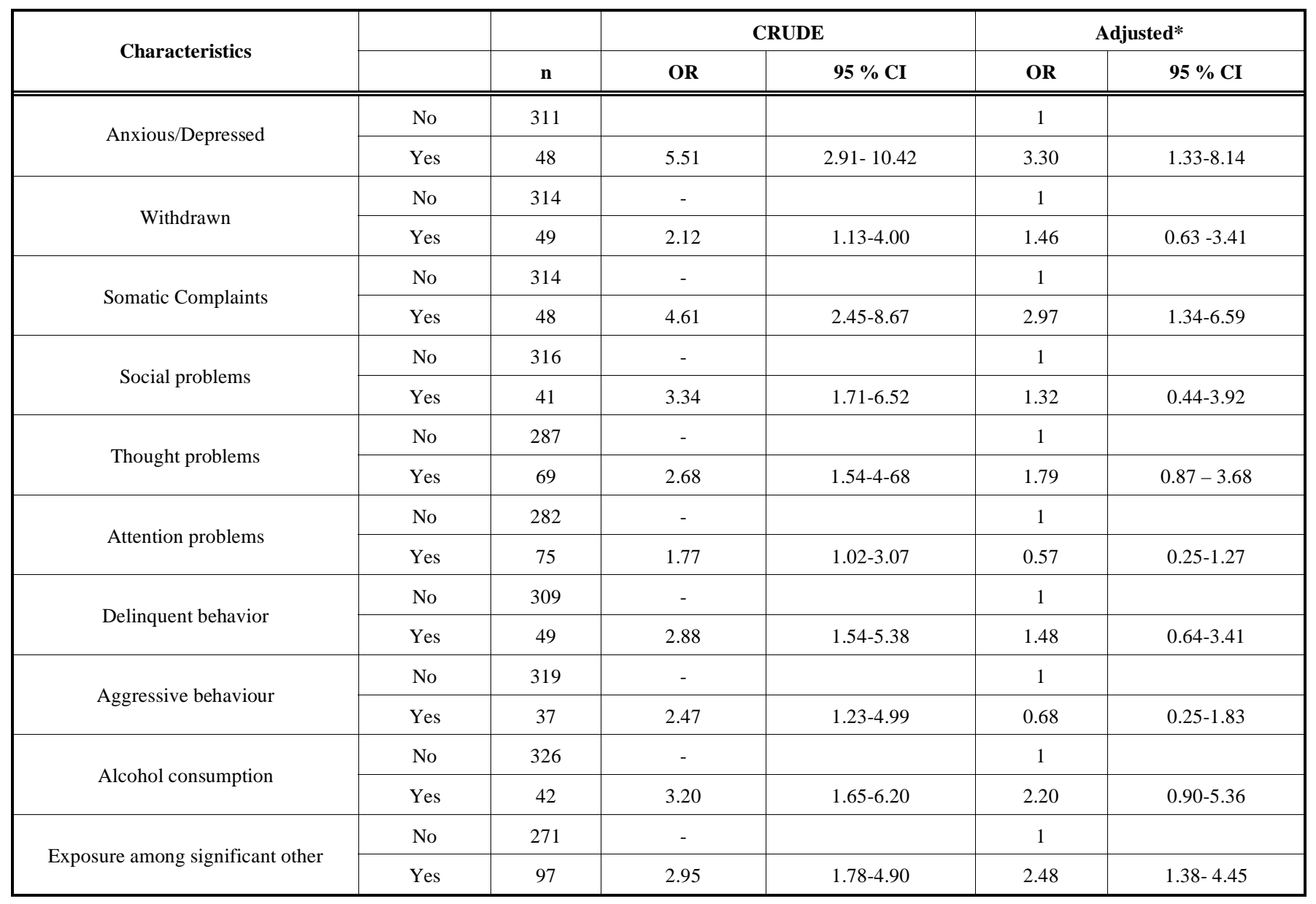


with some of them dying at the first attempt [44]. It might also be that, based on expected gender roles, boys are less likely to report suicidal expressions $[16,44]$.

Overall, the Nicaraguan respondents scored higher on YSR syndromes than reported from normative U.S. samples [37]. For dichotomized YSR syndromes all showed significant unadjusted odds ratios for serious suicidal expressions except for withdrawn, though problems and attention problems. In our multivariate analysis where we also controlled for exposure to suicide in significant others, anxious/depressed, somatic complaints remained independently associated with serious suicidal expressions. Similar findings were reported in a previous study from China, which concluded that internalizing syndrome (e.g., anxious/depressed, somatic complaints) may mediate the effects on suicidal behavior [42].

Exposure to suicidal behavior in our study was associated with serious suicidal expression in both genders. In accordance with a Chinese hospital-based study that having a relative or associate with a history of suicidal behavior was associated with high-intent acts of suicide attempt [29]. Similar findings have been reported in a New Zealand school-based study [9], as well as in a U.S. study which found a strong association between having a friend or relative with an attempted or completed suicide and a history of own attempted suicide (OR 3.80 for boys, 4.52 for girls) [27]. A Nicaraguan study [16] has reported similar findings, but only for having a friend who attempted or completed suicide. What the current study adds, through its multivariate analyses and by including mental health problems in the analyses, is that the exposure has an effect on own suicidal expressions independent of concurrent mental health problems.

\section{METHODOLOGICAL CONSIDERATIONS}

The generalizability of our findings is somewhat limited by the fact that only young people attending school were included. It is estimated that $48.5 \%$ females and $55.3 \%$ males in Leon municipality aged $15-18$ do not attend school (at national level 50.7\% females and 56.9\% males). Another obvious limitation is the cross-sectional design of both our and other studies, where caution is needed when discussing causal relations. Although it seems most likely that exposure has preceded their current suicidal thoughts, the temporal relation between mental symptoms and suicidal expressions cannot be fully clarified.

The different time frames for our assessments (recent six months for YSR-symptoms and recent 12 months for suicidal expressions) might have introduced a bias but it is less likely to have any significant influence of our results.

The strength of the study is that it is the first in a lowincome country to assess the relationship between emotional/behavioral problems, mental health problems, exposure to suicide and serious suicidal behavior in multivariate analyses.

\section{CONCLUSIONS}

The finding that exposure to suicide in significant others is associated with increased own suicidal expressions even in the absence of mental health symptoms is important. Young people who have experienced an attempted or completed suicide in someone close to them must be given appropriate support even when there are few or no signs of mental distress. Somatic complaints by themselves were associated with suicidal problems; health services should therefore be made aware that these are potential markers for a suicidal problem

\begin{tabular}{|c|c|c|}
\hline \multicolumn{3}{|c|}{ ABBREVIATIONS } \\
\hline YSR & $=$ & Youth Self-Report \\
\hline ATTS & $=$ & Attitudes Towards Suicide \\
\hline ASEBA & $=$ & $\begin{array}{l}\text { Achenbach System of Empirically } \\
\text { Based Assessment }\end{array}$ \\
\hline EPI & $=$ & $\begin{array}{l}\text { Info- Statistical software for epidemiol- } \\
\text { ogy }\end{array}$ \\
\hline SPSS & $=$ & $\begin{array}{l}\text { Statistical Package for the Social Sci- } \\
\text { ences }\end{array}$ \\
\hline $\mathrm{ROC}$ & $=$ & Receiver Operating Characteristic \\
\hline AUC & $=$ & Area Under the Curve \\
\hline UNAN & $=$ & $\begin{array}{l}\text { Universidad Nacional Autonoma de } \\
\text { Nicaragua }\end{array}$ \\
\hline
\end{tabular}

\section{ACKNOWLEDGEMENTS}

This study was supported by the Swedish International Development Cooperation Agency/Swedish Agency for Research Cooperation and the Global Health Research School, Umeå University, Sweden. The authors would like to thank all the informants for their participation in this study.

\section{REFERENCES}

[1] WHO. Suicide rates by gender and age group: country reports and charts. Available at: http://www.who.int/mental_health/prevention/suicide/country_reports/en/index.html.

[2] WHO. Preventing suicide. A resource for police, firefighters and other first line responders. Geneva, Switzerland: World Health Organization. 2009.

[3] Bertolote JM, Fleischmann A. A global perspective in the epidemiology of suicide. Suicidol 2002; 7: 6-8.

[4] Krug EG, Mercy JA, Dahlberg LL, Zwi AB. The world report on violence and health. Lancet 2002; 360: 1083-8.

[5] Nordström P, Samuelsson M, Asberg M. Survival analysis of suicide risk after attempted suicide. Acta Psychiatr Scand 1995; 91: 336-40.

[6] Kessler RC, Borges G, Walters EE. Prevalence of and risk factors for lifetime suicide attempts in the national comorbidity survey. Arch Gen Psychiatry 1999; 56: 617-26.

[7] Brent DA. Risk factors for adolescent suicide and suicidal behavior: Mental and substance abuse disorders, family environmental factors, and life stress. Suicide Life Threat Behav 1995; 25(Suppl.): 52-63.

[8] Wichstrom L. Predictors of adolescent suicide attempts: A nationally representative longitudinal study of Norwegian adolescents. J Am Acad Child Adolesc Psychiatry 2000; 39: 603-10.

[9] Fleming TM, Merry SN, Robinson EM, Denny SJ, Watson PD. Self-reported suicide attempts and associated risk and protective factors among secondary school students in New Zealand. Aust N Z J Psychiatry 2007; 41: 213 -21.

[10] Pelkonen M, Marttunen M. Child and adolescent suicide: epidemiology, risk factors, and approaches to prevention. Paediatr Drugs 2003; 5: 243-65.

[11] Sidhartha T, Jena S. Suicidal behaviors in adolescents. Indian J Pediatr 2006; 73: 783-8. 
[12] Kessler RC, Berglund P, Borges G, Nock M, Wang PS. Trends in suicide ideation, plans, gestures, and attempts in the United States, 1990-1992 to 2001-2003. JAMA 2005; 293: 2487-95.

[13] Pillai A, Andrews T, Patel V. Violence, psychological distress and the risk of suicidal behaviour in young people in India. Int J Epidemiol 2009; 38: 459-69.

[14] Arun P, Chavan BS. Stress and suicidal ideas in adolescent students in Chandigarh. Indian J Med Sci 2009; 63: 281-7.

[15] Page RM, Dennis M, Lindsay GB, Merrill RM. Psychosocial distress and substance use among adolescents in four countries: Philippines, China, Chile, and Namibia. Youth Soc 2010; 20: 1-31.

[16] Rodríguez AH, Caldera T, Kullgren G, Renberg ES. Suicidal expressions among young people in Nicaragua. Soc Psychiatry Psychiatr Epidemiol 2006; 41: 692-7.

[17] Ziaaddini H, Navadeh S, Saeedi A. Prevalence of suicide ideation, attempts and the associated factors among a sample of Iranian population in south part of the country: A population based study. Iran J Psychiatry 2009; 4: 92-6.

[18] Eaton DK, Kann L, Kinchen S, et al. Youth risk behavior surveillance - United States, 2005. J Sch Health 2006; 76: 353-72.

[19] Nock MK, Borges G, Bromet EJ, Cha CB, Kessler RC, Lee S. Suicide and suicidal behavior. Epidemiol Rev 2008; 30: 133-54

[20] Gould M, Greenberg T, Velting DM, Shaffer D. Youth suicide risk and preventive interventions: a review of the past 10 years. J Am Acad Child Adolesc Psychiatry 2003; 42: 386-405.

[21] Hawton K. Sex and suicide: Gender differences in suicidal behaviour. Br J Psychiatry 2000; 177: 484-5.

[22] Roberts RE, Chen YR, Roberts CR. Ethnocultural differences in prevalence of adolescent suicidal behaviors. Suicide Life Threat Behav 1997; 27: 208-17.

[23] PAHO. Health Statistics from the Americas. Geneva, Switzerland: Pan American Health Organization; 2006.

[24] Fleischmann A, Bertolote JM, De Leo D, et al. Characteristics of attempted suicides seen in emergency-care settings of general hospitals in eight low- and middle-income countries. Psychol Med 2005; 35: 1467-74.

[25] Caldera T, Herrera A, Renberg ES, Kullgren G. Parasuicide in a low-income country: results from three-year hospital surveillance in Nicaragua. Scand J Public Health 2004; 32: 349 - 55.

[26] Evans E, Hawton K, Rodham K. Factors associated with suicidal phenomena in adolescents: A systematic review of populationbased studies. Clin Psychol Rev 2004; 24: 957-79.

[27] Borowsky IW, Resnick MD, Ireland M, Blum RW. Suicide attempts among American Indian and Alaska native youth: Risk and protective factors. Arch Pediatr Adolesc Med 1999; 153: 573-80.

[28] Remafedi G, French S, Story M, Resnick MD, Blum R. The relationship between suicide risk and sexual orientation: Results of a population-based study. Am J Public Health 1998; 88: 57-60.

[29] Conner KR, Phillips MR, Meldrum SC. Predictors of low-intent and high-intent suicide attempts in rural china. Am J Public Health 2007; 97: 1842-6.
[30] Bridge JA, Goldstein TR, Brent DA. Adolescent suicide and suicidal behavior. J Child Psychol Psychiatry 2006; 47: 372-94.

[31] INEC. VIII Censo de poblacion y IV de vivienda. Poblacion Municipios. Instituto Nacional de Estadisticas y Censos: Nicaragua, 2006.

[32] Dahlblom K: Home alone: sibling caretakers in León, Nicaragua. $\mathrm{PhD}$ thesis 2008. New Series No 1210. Available at: [http://umu.diva-

portal.org/smash/record.jsf?searchId=1\&pid=diva2:142280] Umeå University, Medical Dissertations.

[33] INEC. Análisis de la situación social y económica de la juventud nicaraguense. Instituto Nacional de Estadisticas y Censos: Nicaragua, 2001.

[34] PAHO. Alcohol, gender, culture and harms in the Americas: PAHO Multicentric Study final report. Washington: Pan American Health Organization, 2007.

[35] INEC. VIII Censo de población y IV de Vivienda. Población Características Educativas. Instituto Nacional de Estadisticas y Censos: Nicaragua, 2006.

[36] Renberg ES, Jacobsson L. Development of a questionnaire on attitudes towards suicide (ATTS) and its application in a Swedish population. Suicide Life Threat Behav 2003; 33: 52-64.

[37] Achenbach TM, Rescorla LA. Manual for the ASEBA school- age forms and profiles. Burlington, VT: University of Vermont Research Center for Children, Youth and Families. 2001.

[38] Rey C, Narring F, Ferron C, Michaud PA. Suicide attempts among adolescents in Switzerland: prevalence, associated factors and comorbidity. Acta Psychiatr Scand 1998; 98: 28-33.

[39] Miauton L, Narring F, Michaud PA. Chronic illness, life style and emotional health in adolescence: results of a cross-sectional survey on the health of 15-20-year-olds in Switzerland. Eur J Pediatr 2003; 162: 682-9.

[40] Yip PS, Liu KY, Lam TH, Stewart SM, Chen E, Fan S. Suicidality among high school students in Hong Kong, SAR. Suicide Life Threat Behav 2004; 34: 284-97.

[41] Sourander A, Helstelä L, Haavisto A, Bergroth L. Suicidal thoughts and attempts among adolescents: a longitudinal 8-year follow-up study. J Affect Disord 2001; 63: 59-66.

[42] Liu X, Tein JY. Life events, psychopathology, and suicidal behavior in Chinese adolescents. J Affect Disord 2005; 86: 195-203.

[43] García-Campayo J, Ayuso-Mateos JL, Caballero L, et al. Relationship of somatic symptoms with depression severity, quality of life, and health resources utilization in patients with major depressive disorder seeking primary health care in Spain. Prim Care Companion J Clin Psychiatry 2008; 10: 355-62.

[44] Pettit JW, Lewinsohn PM, Seeley JR, Roberts RE, Hibbard JH, Hurtado AV. Association between the center for epidemiologic studies depression scale (CES-D) and mortality in a community sample: An artifact of the somatic complaints factor? Int J Clin Health Psychol 2008; 8: 383-97.

(C) Medina et al.; Licensee Bentham Open.

This is an open access article licensed under the terms of the Creative Commons Attribution Non-Commercial License (http://creativecommons.org/licenses/by-nc/3.0/) which permits unrestricted, non-commercial use, distribution and reproduction in any medium, provided the work is properly cited. 